\title{
PReS-FINAL-2331: Low-penetrance NLRP3 variants
}

\author{
T Endres ${ }^{1}$, F Hofer ${ }^{1}$, R Goldbach-Mansky ${ }^{2}$, HM Hoffman ${ }^{3}$, N Blank ${ }^{4}$, K Krause $^{5}$, C Rietschel ${ }^{6}$, G Horneff ${ }^{7}$, P Lohse ${ }^{8}$, \\ J Kuemmerle-Deschner ${ }^{1 *}$
}

From 20th Pediatric Rheumatology European Society (PReS) Congress

Ljubljana, Slovenia. 25-29 September 2013

\section{Introduction}

Cryopyrin-associated periodic syndrome (CAPS) presents as rare, autosomal dominant disease spectrum, due to mutations in the NLRP3-gene which lead to excessive interleukin-1 (IL-1) release.

In patients with low-penetrance NLRP3 variants, the clinical presentation varies widely. So far, a correlation with a specific phenotype could not be demonstrated.

\section{Objectives}

The aim of this study was to analyze the association of the V198M, R488K, and Q703K substitutions with a specific phenotype, laboratory markers, and the response to IL-1 inhibitors anakinra, canakinumab and rilonacept.

\section{Methods}

This multi-center observational study included 45 patients (26 children and 19 adults) (study group). At baseline examination, all patients displayed some symptoms suggestive of CAPS. Genetic analysis detected one of the following NLRP3 variants: Q703K ( $n=19)$, R488K ( $n=6)$, and V198M $(n=20)$.

Clinical presentation was recorded and inflammation markers were analyzed. Data from follow-up visits were also evaluated to assess response to IL-1 inhibitors. Results were compared to a (control) group of CAPS patients $(n=28)$ in which disease-causing mutations had been confirmed (A439V, E311K, T348M).

\section{Results}

At baseline examination, study patients reported signs of systemic inflammation such as fever (76\%), headache (73\%), musculoskeletal symptoms (84\%) and fatigue (78\%). Other CAPS-specific features were rash (80\%), conjunctivitis (44\%) and sensorineural hearing loss (29\%).

\footnotetext{
'Department of Pediatrics, Division of Pediatric Rheumatology, University Hospital Tuebingen, Tuebingen, Germany Full list of author information is available at the end of the article
}

Compared to the control group, a history of eye impairment, hearing loss and renal involvement was significantly less frequent in the study group. However study group patients presented significantly more often with gastrointestinal symptoms such as abdominal pain (56\% versus $25 \%, \mathrm{p}=0.01$ ) and gastroesophageal reflux ( $22 \%$ versus $0 \%, \mathrm{p}=0.01$ ). Also, a wide spectrum of concomitant diseases such as thyroid disorders (7) and neurological and psychiatric diseases were reported (epilepsy (3), Asperger syndrome (2)).

Inflammation markers were only slightly increased: ESR was elevated in 26\% (9/35) and C-reactive protein (CRP) in $34 \%(14 / 41)$. Serum amyloid A (SAA) was raised in 36\% $(8 / 22)$ of the patients. Nine out of ten patients $(90 \%)$ had elevated TNF- $\alpha$-levels at baseline examination.

Data from follow-up visits during the first year of treatment was available from 20 patients, treated with IL1 - inhibitors. Clinical disease activity was reduced in all cases; 10 patients (50\%) achieved full remission and 10 patients showed partial response to the treatment with mild disease activity and/ or persistently elevated inflammation markers.

\section{Conclusion}

Heterozygous carriers of the NLRP3 variants V198M, $\mathrm{R} 488 \mathrm{~K}$, and Q703K display distinct clinical characteristics compared to CAPS patients with confirmed disease causing mutations, including a high incidence of gastrointestinal symptoms, only slightly elevated inflammatory parameters, and a potentially inferior response to IL-1 inhibition. Also susceptibility for concomitant diseases is observed.

\section{Disclosure of interest}

None declared.

\section{Authors' details}

${ }^{1}$ Department of Pediatrics, Division of Pediatric Rheumatology, University Hospital Tuebingen, Tuebingen, Germany. ${ }^{2}$ Translational Autoinflammatory 
Disease Section, NIAMS/NIH, Bethesda, MD, USA. ${ }^{3}$ Division of Rheumatology and Allergy/Immunology, University of California at San Diego, San Diego

CA, USA. ${ }^{4}$ Hämatologie, Onkologie u. Rheumatologie, Universitätsklinikum Heidelberg, Heidelberg, Germany. "Allergie-Centrum Charité", Klinik für Dermatologie, Charité Campus Mitte, Berlin, Germany. ${ }^{6}$ Kinder-und Jugendrheumatologie, Clementine-Kinderhospital, Frankfurt, Germany. ${ }^{7}$ Abteilung für Allgemeine Kinder-und Jugendmedizin, Asklepios-Klinik Sankt Augustin, Sankt Augustin, Germany. ${ }^{8}$ Institut für Laboratoriumsmedizin und Humangenetik, Singen, Germany.

Published: 5 December 2013

doi:10.1186/1546-0096-11-S2-P321

Cite this article as: Endres et al:: PReS-FINAL-2331: Low-penetrance NLRP3 variants. Pediatric Rheumatology 2013 11(Suppl 2):P321.

Submit your next manuscript to BioMed Central and take full advantage of:

- Convenient online submission

- Thorough peer review

- No space constraints or color figure charges

- Immediate publication on acceptance

- Inclusion in PubMed, CAS, Scopus and Google Scholar

- Research which is freely available for redistribution

Submit your manuscript at www.biomedcentral.com/submit
() BioMed Central 